\title{
Determinants on Dental Caries Among Pregnant Mothers in Medical Officer of Health Area, Ambalantota, Sri Lanka
}

\author{
Lasantha Krishan Hirimuthugoda ${ }^{1,}$, Jayasekara Liyana Patabendige Chaminda ${ }^{2}$, \\ Nilani Priyadarshika Gunasekara ${ }^{2}$, Hewa Julige Madhuwanthi Samarapala², \\ Suwandha Hannadhige Manusha Kumari ${ }^{2}$, Iresha Lakmali Pathirana ${ }^{2}$, \\ Bragmanage Badrani Samantha Ramachandra ${ }^{1}$, Sudirikku Hennadige Padmal De Silva ${ }^{3}$ \\ ${ }^{1}$ Post Graduate Institute of Medicine, University of Colombo, Colombo, Sri Lanka \\ ${ }^{2}$ Department of Health, Ministry of Health, Colombo, Sri Lanka \\ ${ }^{3}$ WHO Country Office, Colombo, Sri Lanka
}

Email address:

krishan824@yahoo.com (L. K. Hirimuthugoda)

${ }^{*}$ Corresponding author

\section{To cite this article:}

Lasantha Krishan Hirimuthugoda, Jayasekara Liyana Patabendige Chaminda, Nilani Priyadarshika Gunasekara, Hewa Julige Madhuwanthi Samarapala, Suwandha Hannadhige Manusha Kumari, Iresha Lakmali Pathirana, Bragmanage Badrani Samantha Ramachandra, Sudirikku Hennadige Padmal De Silva. Determinants on Dental Caries Among Pregnant Mothers in Medical Officer of Health Area, Ambalantota, Sri Lanka. International Journal of Dental Medicine. Vol. 4, No. 1, 2018, pp. 5-8. doi: 10.11648/j.ijdm.20180401.12

Received: January 13, 2018; Accepted: February 9, 2018; Published: March 6, 2018

\begin{abstract}
Introduction: The negative health effects of dental caries are cumulative, tracking from childhood to adulthood and most dental caries is now occurring in adults [1-3]. Oral diseases such as dental caries, gingivitis, and periodontal diseases can occur during pregnancy [4-9]. This study was carried out in Medical officer of health (MOH) area, Ambalantota, Sri Lanka. 363 pregnant women in first visit attending antenatal clinic were recruited. Written informed consent was obtained from all subjects who agreed to take part in the study. Ethical approval was taken from faculty of Medicine, University of Ruhuna. Prior to a dental examination, demographic information regarding age, education, occupation, socioeconomic status and residence were obtained from the participants using interviewer administered questionnaire. Findings of dental examination were entered examination table separately. The mean DMFT among antenatal women was $3.8 \pm 5.17$, with $3.27( \pm 2.31)$ decayed teeth, $1.85( \pm 1.87)$ missing teeth, and $1.4( \pm 1.4)$ filled teeth. Results were shown in table 3 with binary logistic analysis of DMFT for the overall sample of 363 pregnant women. The final model explained $6.3 \%$ to $8.4 \%$ of DMFT variation (dependant variable) with variation of independent variables (educational level up to Ordinary level, Sinhla over non-sinhala, income over 30,000, knowledge on dental services free by government and ever taken treatment) and the p-value for HosmerLemeshow test of goodness of fit was 0.957 , which indicated an acceptable fit of the model. In the final model significant predictors were Sinhala: Non-sinhala (adjusted OR [95\% CI]: 5.67 [1.25-25.99], $\mathrm{p}=0.026$ ) and "ever taken treatment for dental diseases"( Yes vs No: adjusted OR [95\% CI]: 0.432 [0.274-0.680], p<0.0001). In this study, pregnant women in Ambalantota $\mathrm{MOH}$ area were found to have a significantly higher DMFT value among Sinhala women over Non- Sinhala women and similarly significantly lower DMFT value among pregnant women who sought treatment for their dental diseases against women who did not.
\end{abstract}

Keywords: Dental Caries, DMFT Value, Pregnant Mothers

\section{Introduction}

Oral health is a key to overall health and well-being, nevertheless, during pregnancy it is often neglected by women, particularly among women of low socioeconomic status [2]. Dental caries causes pain, anxiety, functional limitation and social handicap through tooth loss. The negative health effects of dental caries are cumulative, 
tracking from childhood to adulthood and most dental caries is now occurring in adults [1-3]. Oral diseases such as dental caries, gingivitis, and periodontal diseases can occur during pregnancy [4-9].

The National Oral Health Survey (2003) gives an indication about the oral healthcare needs of the females in the reproductive age group. It has been reported that $47.2 \%$ of the 15 -year-old females and $78.4 \%$ of those in the $34-44$ year-old age group have active dental caries. Accordingly 47 - $80 \%$ of pregnant mothers may need treatment for dental caries. The same survey also showed that $74.8 \%$ and $88.8 \%$ in the above age groups respectively required some form of periodontal care. This gives the magnitude of the problem regarding periodontal diseases of pregnant mothers.

All pregnant women who visit antenatal clinics are referred to the nearest public dental clinic for oral health screening and necessary care in Sri Lanka. Therefore, improving the oral health status of pregnant women could prevent the complications of dental diseases during pregnancy, may reduce adverse pregnancy outcomes, the maternal and infant morbidity associated with Gestational Diabetic Mellitus and has the potential to reduce the incidence of Early Childhood Caries, which is a public health problem in many countries, including Sri Lanka [2-4, 6, 10, 11].

Study done in Baghdad revealed a higher caries experience (DMFS) among pregnant women compared to non-pregnant group but with no statistically significant difference. Caries experience (DMFS) showed a highly significant difference with pregnant educational level [7, 12]. The compromised functional status, physical confinement, medical condition and cognitive impairment of significant numbers of women have important implications for oral health risks and dental treatment, in addition there are a variety of economic, social, psychological and behavioural factors which place pregnant women at risk for developing oral diseases [11].

The objective of this study was to assess the occurrence of dental caries in the oral cavity of pregnant women and, to find associations with socio-economic status, knowledge on availability of dental services and utility of free dental health services given by government of Sri Lanka.

\section{Methods}

The study was carried out in Medical officer of health $(\mathrm{MOH})$ area, Ambalantota, Sri Lanka. 363 pregnant women in first visit attending antenatal clinic were recruited. Written informed consent was obtained from all subjects who agreed to take part in the study. Ethical approval was taken from faculty of Medicine, University of Ruhuna. Prior to a dental examination, demographic information regarding age, education, occupation, socioeconomic status and residence were obtained from the participants using interviewer administered questionnaire. Findings of dental examination was entered examination table separately. Dental caries and gingivitis were defined according to the WHO criteria; "newly developed cavity" (dental caries) and "gingival bleeding on probing” (gingivitis).

\section{Results}

Out of 363 pregnant mothers, 187 (51.5\%) were having dental caries and $9.1 \%$ of pregnant women were teenagers while $30.1 \%$ were in $26-30$ years of age category. Sociodemographic characteristics were presented in Table 1.

Table 1. Socio-Demographic characteristics of pregnant women.

\begin{tabular}{|c|c|c|}
\hline Socio demographic characteristic & No. & $\%$ \\
\hline \multicolumn{3}{|l|}{ 1. Current marital status } \\
\hline married & 360 & 99.0 \\
\hline unmarried & 2 & .6 \\
\hline widowed & 1 & .3 \\
\hline \multicolumn{3}{|l|}{ 2. Nationality } \\
\hline Sinhala & 347 & 95.6 \\
\hline Tamil & 1 & 0.3 \\
\hline Moor & 12 & 3.3 \\
\hline Christian & 3 & 0.8 \\
\hline \multicolumn{3}{|l|}{ 3. Education level } \\
\hline No schooling & 2 & 0.6 \\
\hline Up to year 5 & 12 & 3.3 \\
\hline Up to $\mathrm{O} / \mathrm{L}$ & 206 & 56.7 \\
\hline Up to $\mathrm{A} / \mathrm{L}$ & 123 & 33.9 \\
\hline Holding a diploma/ degree & 20 & 5.5 \\
\hline \multicolumn{3}{|l|}{ 4. Monthly family income level (Rs.) } \\
\hline No income & 14 & 3.9 \\
\hline$<\mathrm{Rs} 5,000$ & 27 & 7.4 \\
\hline Rs5,001-10,000 & 83 & 22.9 \\
\hline Rs10,001-20,000 & 76 & 20.9 \\
\hline $20,001-30,000$ & 105 & 28.9 \\
\hline$>$ Rs30,000 & 58 & 16.0 \\
\hline
\end{tabular}

One way anova was used to test the significance between different nationalities, different income levels and different educational status over number of dental caries. There was significant difference between nationalities over dental caries $(\mathrm{F}=5.734, \mathrm{P}=0.001)$. We found no significance in educational status and income levels over number of dental caries $(\mathrm{F}=0.838, \mathrm{P}>0.05, \mathrm{~F}=0.754, \mathrm{p}>0.05)$.

Among participants, $176(48 \%)$ of Sinhalese were having dental caries, while $11(3 \%)$ of non-sinhalese were not having. There was no significant difference between them on presence on dental caries. Pregnant women who have ever taken treatment for dental diseases were having significantly higher percentage of women with dental diseases over pregnant women with dental diseases, who have not ever taken treatment for dental diseases $(\mathrm{p}<0.0001)$. Findings were presented in table 2 . 
Table 2. Characteristics of pregnant mothers and knowledge and utility of dental services over dental diseases.

\begin{tabular}{|c|c|c|c|}
\hline \multirow{2}{*}{ Characteristics/ utility of Dental services } & \multicolumn{2}{|c|}{ Status of dental diseases $(\mathrm{N}=\mathbf{3 6 3})$} & \multirow{2}{*}{ p value } \\
\hline & Present & Absent & \\
\hline \multicolumn{4}{|l|}{ Nationality } \\
\hline Sinhala & $176(48 \%)$ & $171(47 \%)$ & $\mathrm{p}=0.49$ \\
\hline Non-sinhala & $11(3 \%)$ & $5(1.3 \%)$ & \\
\hline \multicolumn{4}{|c|}{ Awareness on availability of free government dental services } \\
\hline Yes & $176(48.8 \%)$ & $159(44 \%)$ & $\mathrm{p}=0.18$ \\
\hline No & $11(3 \%)$ & $17(4.7 \%)$ & \\
\hline \multicolumn{4}{|l|}{ Ever taken any dental treatment for dental diseases } \\
\hline Yes & $95(26 \%)$ & $126(34.7 \%)$ & $\mathrm{p}<0.0001$ \\
\hline No & $92(25.3 \%)$ & $50(13.8 \%)$ & \\
\hline \multicolumn{4}{|c|}{ Usually taking treatment from free government dental services } \\
\hline Yes & $162(44.6 \%)$ & $152(41.8 \%)$ & $\mathrm{p}=0.767$ \\
\hline No & $11(3 \%)$ & $9(2.5 \%)$ & \\
\hline
\end{tabular}

Descriptive analysis was used to depict the opinion among participants on, why they were not using free government dental services. Out of 124 participants, majority (49.2\%) indicated that government dental clinics were crowded and $45(36.3 \%)$ reported, that dental clinics were having long waiting time for consultations. About $4 \%$ indicated on difficulty in taking appointment for consultations. There were less than $3 \%$ responses for each statements, indicating "not having sitting facility", "low quality of treatment" and "concerns on safety issues of treatment".

The mean DMFT among antenatal women were $3.8 \pm$ 5.17, with $3.27( \pm 2.31)$ decayed teeth, $1.85( \pm 1.87)$ missing teeth, and $1.4( \pm 1.4)$ filled teeth. Results are shown in table 3 with binary logistic analysis of DMFT for the overall sample of 363 pregnant women. The final model explained $6.3 \%$ to $8.4 \%$ of DMFT variation (dependant variable) with variation of independent variables (educational level up to Ordinary level, Sinhla over non-sinhala, income over 30,000, knowledge on dental services free by government and ever taken treatment) and the p-value for Hosmer-Lemeshow test of goodness of fit was 0.957 , which indicated an acceptable fit of the model. In the final model significant predictors were Sinhala: Non-sinhala (adjusted OR [95\% CI]: 5.67 [1.25-25.99], $\mathrm{p}=0.026)$ and "ever taken treatment for dental diseases" (Yes vs No: adjusted OR [95\% CI]: 0.432 [0.2740.680], $\mathrm{p}<0.0001)$.

Table 3. Frequency distribution for logistic regression analyses for dental caries experience: predictors of the final model.

\begin{tabular}{|c|c|c|}
\hline \multirow{2}{*}{ Variable } & \multicolumn{2}{|l|}{ Analysis } \\
\hline & OR (ß) & $95 \% \mathrm{CI}$ \\
\hline 1. Education level Educated up to $\mathrm{O} / \mathrm{L}$ vs above $\mathrm{O} / \mathrm{L}$ & $0.839(-0.178)$ & $(0.533-1.321)$ \\
\hline 2. Income level Income up to 30,000 LKR vs above 30,000 LKR & $0.985(-0.015)$ & $(0.537-1.807)$ \\
\hline 3. Nationality - Sinhala vs Non-Sinhala & $5.666(1.714)$ & $(1.235-25.991)$ \\
\hline 4. Knowledge on availability of free dental services provided by government - Yes / No & $2.087(0.736)$ & $(0.918-4.744)$ \\
\hline 5. Ever taken any dental treatment for dental diseases - Yes / No & $0.432(-0.840)$ & $-0.680)$ \\
\hline
\end{tabular}

\section{Discussion}

Prevalence of dental caries among pregnant mothers in Ambalantota $\mathrm{MOH}$ area was $48.5 \%$, whereas Hassan Falil et al., discussed the study done in Iraq as prevalence was $74 \%$ [11]. Study done in Sri Lanka including about 800 pregnant women showed prevalence $91.7 \%$ for rural women, and $81.3 \%$ for urban women [10]. Finding related to DMFT mean value of our study participants were 3.8 with \pm 5.17 . But study done in Brazil among 120 pregnant mothers showed DMFT mean value as $12.1 \pm 6.2$ [8]. Karunachandra et al., discussed their finding related to DMFT. The mean DMFT among rural antenatal women were $5.4 \pm 3$, indicating that average 5 teeth were affected among rural pregnant women with at least 2 of these teeth having untreated dental caries. Among the urban pregnant women, the mean DMFT was $3.69( \pm 3.62)$, indicating 4 teeth were affected by dental caries, one of which had untreated dental caries [10]. A higher occurrence of dental caries was noted among those who were low education level than those who had educated and also Sinhala mothers over non-Sinhala mothers. The high prevalence of dental caries in the low socio-economic status is because of their poor oral hygiene practice, lack of awareness, improper food intake and family status. Similar finding were explained in study of Mital et al,. as illiterate women (Odd ratio 1.79; 95\% CI 1.07 - 2.99; p value - 0.02), belonging to rural area (Odd ratio 2.14; 95\% CI 1.27 - 3.59; $\mathrm{p}$ value - 0.004 ) and house wife (Odd ratio $2.49 ; 95 \%$ CI 1.47 -4.22 ; $p$ value -0.015$)$ were having higher values than their counterpart [5].

\section{Conclusions}

Pregnancy is an important milestone in a women's life and it indicates an increased need for dental care, among other health needs. In this study, pregnant women in Ambalantota $\mathrm{MOH}$ area were found to have a significantly higher DMFT 
value among Sinhala women over Non- Sinhala women and similarly significantly lower DMFT value among pregnant women who sought treatment for their dental diseases against women who did not. There were no significant differences in other variables. Therefore, all pregnant mothers should encourage to seek dental advices for their dental diseases and Sinhala pregnant women should be highly motivated on keeping good oral hygiene through oral health care services for pregnant women in Sri Lanka.

\section{Abbreviations}

MOH: Medical officer of Health; DMFT: Decaying, Missing, Filling teeth; O/L: Ordinary Level; A/L: Advanced Level;

\section{Declarations}

Written informed consent was obtained from all subjects who agreed to take part in the study.

\section{Ethical Approval}

Ethical approval was taken from Ethics Review committee, Faculty of Medicine, University of Ruhuna. Prior to a dental examination, demographic information regarding age, education, occupation, socioeconomic status and residence were obtained from the participants using interviewer administered questionnaire.

\section{Consent for Publication}

Not applicable.

\section{Availability of Data and Materials}

Presented with in manuscript as an additional file.

\section{Competing Interests}

The authors declare that they have no competing interests.

\section{Authors' Contributions}

LK and RB are responsible for reported research. Both authors have made substantial contributions to conception and design; analysis and interpretation of data and drafting and revising it critically for important intellectual content. Both authors read and approved the final manuscript. JL, NP, $\mathrm{HJ}$, SH and IL contributed by examining participants oral health, collecting, refining, entering and sorting the data.

\section{Acknowledgements}

The study reported here were self-funded and the authors alone are responsible for the content and writing of this article. The guidance given by Dr H.S.K. Rathnathilaka, Consultant Orthodontist, Teaching hospital, Kegalle, Sri Lanka is gratefully appreciated. The authors are also grateful to the participants and the health staff in the region.

\section{References}

[1] WHO. Reducing free sugars intake in adults to reduce the risk of noncommunicable diseases. 2017 [cited 2017 02/01/2018].

[2] Wagner, Y. and R. Heinrich-Weltzien, Midwives' oral health recommendations for pregnant women, infants and young children: results of a nationwide survey in Germany. BMC Oral Health, 2016. 16: p. 36.

[3] Rakchanok, N., et al., Dental caries and gingivitis among pregnant and non-pregnant women in Chiang Mai, Thailand. 2010 .

[4] Azofeifa, A., et al., Dental caries and periodontal disease among U.S. pregnant women and nonpregnant women of reproductive age, National Health and Nutrition Examination Survey, 1999-2004. Journal of Public Health Dentistry, 2016. 76(4): p. 320-329.

[5] Mital, P., Dental caries and gingivitis in pregnant women. Age, 2013. 25(25): p. 166.

[6] Shaghaghian, S., et al., Dental caries status and its associated factors in pregnant women, Shiraz, Iran, 2014. Journal of Oral Health and Oral Epidemiology, 2017. 6(3): p. 165-172.

[7] Yas, B. A. and L. Al-Azzawi, Evaluation of dental caries experience and treatment needs of pregnant women in Baghdad governorate. Journal of Baghdad College of Dentistry, 2007. 19(1): p. 107-111.

[8] Moimaz, S. A., et al., Influence of oral health on quality of life in pregnant women. Acta Odontol Latinoam, 2016. 29(2): p. 186-193.

[9] Ziskin, D. E., The incidence of dental caries in pregnant women. American Journal of Obstetrics and Gynecology, 1926. 12(5): p. 710-719.

[10] Karunachandra, N. N., I. R. Perera, and G. Fernando, Oral health status during pregnancy: rural-urban comparisons of oral disease burden among antenatal women in Sri Lanka. Rural Remote Health, 2012. 12(3): p. 1902.

[11] AL-Sultani, H. F. F., Prevalence and Severity of Dental Caries, Periodontal Diseases and Dental Erosion among (20 40) Years Old Pregnant Women in Hilla city, Babylon governorate-Iraq. health, 2013. 5(6): p. 7.

[12] Gaszynska, E., et al., Dental awareness and oral health of pregnant women in Poland. Int J Occup Med Environ Health, 2015. 28(3): p. 603-11. 